\title{
Técnica rápida de neutralização viral para a detecção de anticorpos contra o vírus da Diarréia Viral Bovina (BVDV) no leite ${ }^{1}$
}

\author{
Charles Fernando Capinos Scherer ${ }^{2}$, Eduardo Furtado Flores ${ }^{3 *}$, Rudi Weiblen ${ }^{4}$, Luiz \\ Carlos Kreutz ${ }^{5}$, João Walter Dürr ${ }^{5}$, Larissa Picada Brum ${ }^{6}$, Valter L. Quadros ${ }^{7}$ \\ e Marcelo de Lima ${ }^{7}$
}

\begin{abstract}
Scherer C.F.C., Flores E.F., Weiblen R., Kreutz L.C., Dürr J.W., Brum L.P., Quadros V.L. \& Lima, M. 2000.|A rapid virus-neutralization test for detection of antibodies against bovine viral diarrhea virus (BVDV) in milk.] Técnica rápida de neutralização viral para pesquisa de anticorpos contra o vírus da Diarréia Viral Bovina (BVDV) no leite. Pesquisa Veterinária Brasileira 20(2):45-50. Departamento de Medicina Veterinária Preventiva, Universidade Federal de Santa Maria, 97105-900 Santa Maria, RS, Brazil.

The identification of bovine viral diarrhea virus (BVDV) positive herds through detection of antibodies in milk may viabilize large scale control/eradication programs. With this objective, the virus neutralization test (VN) was adapted to detect BVDV antibodies in milk. The adaptation consisted of a reduction in the time of incubation followed by detection of viral antigens in the indicator cells by immunofluorescence (IFA) and allowed readings at 24 hours. The rapid virus neutralization test (RVN) was initially tested in 1,335 serum samples, showing a $93.7 \%$ sensitivity and $91.1 \%$ agreement with the traditional VN. The RVN was also used to test 423 bovine sera that were toxic for cell culture in the traditional VN test, detecting $316(74.7 \%)$ positive samples. Testing of matched serum and milk samples from BVDV seropositive cows showed that the VNR can detect antibodies in the milk of cows with serum neutralizing titers as low as 10 . Anti-BVDV neutralizing activity was detected in milk of $97.4 \%(191 / 196)$ of cows with serum titers ${ }^{3320}$; in $92.9 \%(79 / 85)$ of cows with titers of 160 ; in $88 \%(59 / 67)$ of cows with serum titers of 80 . The frequency of BVDV antibodies in milk was $76.9 \%(40 / 52)$ for cows with serum titers of $40 ; 61.3 \%$ (19/31) for cows with titers of 20 and $33.3 \%(10 / 30)$ for cows with serum titers of 20. These results demonstrate that the RVN test is adequate for detecting BVDV antibodies in milk, mainly in cows having moderate to high serum titers, and therefore may be used for testing bulk milk samples to identify herds with viral activity. The use of this test may viabilize large scale programs for control/eradication of BVDV infection. It allows to assay a large number of samples and identify positive herds through testing milk routinely submitted for somatic cell counts (SCC), reducing costs with individual sample collection, shipping and testing.
\end{abstract}

INDEX TERMS: Bovine viral diarrhea virus, BVDV, diagnosis, antibodies, milk.

\footnotetext{
${ }^{1}$ Aceito para publicação em 8 de março de 2002.

Trabalho realizado com suporte financeiro do MCT, CNPq, Capes e Finep (Pronex em Virologia Veterinária, 215/96).

${ }^{2}$ Departamento de Microbiologia e Parasitologia, Centro de Ciências da Saúde, Universidade Federal de Santa Maria (UFSM).

${ }^{3}$ Departamento de Medicina Veterinária Preventiva, Centro de Ciências Rurais, e do Departamento de Microbiologia e Parasitologia, UFSM, 97105900 Santa Maria, RS. Bolsista do CNPq (520758/96-0). Fone/fax: 55-220-8034. E-mail: flores@ccr.ufsm.br. *Autor para correspondência.
}

\footnotetext{
${ }^{4}$ Departamento de Medicina Veterinária Preventiva, e do Departamento de Microbiologia e Parasitologia, UFSM. Bolsista do CNPq (520161/97-1).

${ }^{5}$ Faculdade de Agronomia e Medicina Veterinária, Universidade de Passo Fundo (UPF), Passo Fundo, RS.

${ }^{6}$ Mestrando em Medicina Veterinária, UFSM.

${ }^{7}$ Estudante do Curso de Medicina Veterinária, UFSM. Bolsista de Iniciação Científica, FAPERGS.

${ }^{8}$ Estudante do Curso de Medicina Veterinária, UFSM. Bolsista de Iniciação Científica, CNPq.
} 
RESUMO.- A identificação de rebanhos positivos para o vírus da Diarréia Viral Bovina (BVDV) através de detecção de anticorpos no leite pode viabilizar programas de controle em larga escala. Com esse objetivo, a técnica de soroneutralização $(\mathrm{SN})$ foi adaptada para a pesquisa de anticorpos em amostras de leite. A adaptação consistiu na redução do tempo de incubação do teste, seguida da detecção de antígenos virais por imunofluorescência. A redução do tempo de incubação minimizou os efeitos tóxicos do leite sobre as células de cultivo, além de permitir a obtenção dos resultados em 24 horas. A técnica rápida (SNR) foi inicialmente testada em 1.335 amostras de soro bovino, apresentando sensibilidade de $93,7 \%$ e concordância de $91,1 \%$ em relação à SN tradicional. A SNR foi também utilizada para testar 423 amostras de soro bovino que apresentaram toxicidade para as células na $\mathrm{SN}$ tradicional, detectando $316(74,7 \%)$ amostras positivas. O teste de amostras de soro e leite de $\mathbf{5 2 0}$ vacas em lactação demonstrou que a SNR pode detectar anticorpos no leite de vacas com títulos séricos a partir de 10. Atividade neutralizante anti-BVDV no leite foi detectada em $97,4 \%(191 / 196)$ de vacas com títulos séricos ${ }^{3} 320$; em 92,9\% (79/85) de vacas com títulos de 160; em 88\% (59/67) de vacas títulos de 80 . A frequiência de animais positivos na SNR foi de 76,9\% (40/52) para animais com títulos séricos de 40; $61,3 \%$ (19/31) com títulos de 20 e de 33,3\% (10/30) para vacas com títulos de 10. Esses resultados demonstram que a técnica de SNR é adequada para a pesquisa de anticorpos antiBVDV no leite, principalmente em animais com títulos moderados e altos de anticorpos. Essa técnica pode ser utilizada para testar amostras coletivas de leite e identificar rebanhos com atividade viral. A utilização dessa técnica pode viabilizar programas regionais de combate à infecção, pois permite testar um grande número de amostras e identificar rebanhos positivos através do leite enviado rotineiramente para contagem de células somáticas (CCS), reduzindo significativamente os custos com a coleta individual, transporte e teste de amostras.

TERMOS DE INDEXAÇÃO: Vírus da Diarréia Viral Bovina, BVDV, diagnóstico, leite, anticorpos.

\section{INTRODUÇÃO}

O vírus da Diarréia Viral Bovina (bovine viral diarrhea virus, BVDV) é um dos patógenos mais importantes de bovinos e causa prejuízos significativos para a pecuária bovina em todo o mundo (Baker 1995). O BVDV é um vírus RNA de polaridade positiva, com envelope, pertencente à família Flaviviridae, gênero Pestivírus (Francki et al. 1991). A infecção pós-natal de bovinos pelo BVDV pode resultar em infecção subclínica, doença respiratória ou digestiva (Diarréia Viral Bovina, BVD), Doença das Mucosas (DM) e BVD aguda/hemorrágica (Corapi et al. 1989, Baker 1995). A infecção de fêmeas prenhes freqüentemente resulta em transmissão transplacentária do vírus, ocasionando perdas embrionárias ou fetais, malformações, mortalidade perinatal e o nascimento de bezerros persistentemente infectados (PI) (Baker 1995). Os animais PI excretam o vírus continuamente e constituem-se na princi- pal fonte de disseminação do vírus (Brownlie 1990, Baker 1995). Por isso, o controle da infecção pelo BVDV deve ser direcionado para a detecção e eliminação dos animais PI, além da vacinação sistemática de fêmeas soronegativas para prevenir a infecção fetal (Dubovi 1992).

Programas de controle e erradicação da infecção pelo BVDV sem o uso de vacinas têm sido implementados em alguns países europeus. Esses programas são voluntários e baseiam-se na identificação de rebanhos infectados e certificação de rebanhos livres, seguidos do descarte dos animais PI das propriedades positivas (Lindberg \& Alenius 1999). Rebanhos que possuem animais PI podem ser identificados por sorologia, já que a presença do vírus resulta em níveis altos de anticorpos na maioria dos animais (Houe 1995). Várias estratégias têm sido utilizadas para a triagem e identificação inicial desses rebanhos: (1) Sorologia de amostras individuais de animais jovens ou de todo o rebanho; (2) Sorologia em amostras coletivas (pool) de soro de animais entre oito e 24 meses de idade; (3) Detecção de anticorpos em amostras individuais de leite; (4) Sorologia em amostras coletivas de leite (Niskanen 1993, Alenius et al. 1996, Paton et al. 1998). Nesses programas, a utilização de um teste imunoenzimático do tipo ELISA para a pesquisa de anticorpos em amostras coletivas de leite tem viabilizado a realização de triagens de rebanhos em grande escala (Niskanen et al. 1991, Paton et al. 1998). Os níveis de anticorpos em amostras coletivas de leite possuem uma boa correlação com a atividade viral e com a proporção de animais soropositivos nos rebanhos (Niskanen 1993, Beaudeau et al. 2001).

A infecção pelo BVDV está amplamente difundida no rebanho bovino do Brasil (Botton et al. 1998, Pituco \& Del Fava 1998, Roehe et al. 1998). Na ausência de programas oficiais de combate à infecção, programas voluntários de controle através de vacinação e eliminação de animais PI têm sido recomendados e ocasionalmente adotados por produtores. Essa prática, no entanto, é ocasional e não sistemática, sendo adotada em uma pequena parcela dos rebanhos. Programas oficiais ou voluntários de controle em grande escala poderiam ser viabilizados técnica e economicamente pela disponibilidade de um teste para triagem e identificação de rebanhos infectados.

Os objetivos desse estudo foram adaptar a técnica sorológica de soro-neutralização $(\mathrm{SN})$ para a detecção de anticorpos no leite. A SN é uma das técnicas sorológicas padrão e tem sido utilizada mundialmente para a deteç̧ão de anticorpos contra o BVDV em amostras de soro (Brock 1995).

\section{MATERIAL E MÉTODOS}

\section{Células e vírus}

Os procedimentos de multiplicação, quantificação de vírus e testes de soro-neutralização (SN) foram realizados com células MDBK (Madin Darby bovine kidney; American Type Culture Collection, CCL22) livres de pestivírus. As células foram cultivadas em meio essencial mínimo (MEM), com penicilina (35mg/L), estreptomicina $(200 \mathrm{mg} / \mathrm{L})$, suplementado com $5 \%$ de soro eqüino. A cepa padrão de BVDV Singer utilizada nos testes de neutralização viral foi cedida pelo Dr Ruben Donis (University of Nebraska, Lincoln, NE, USA). 


\section{Amostras de soro e leite}

Foram testadas 1758 amostras de soro bovino, pertencentes a propriedades do Estado do Rio Grande do Sul, enviadas ao Setor de Virologia da UFSM para pesquisa de anticorpos contra o BVDV. Dessas amostras, 423 haviam sido previamente consideradas tóxicas para as células de cultivo na SN tradicional. Para a detecção de anticorpos no soro e leite foram testadas amostras coletadas de 520 vacas em lactação, provenientes de 12 rebanhos leiteiros localizados na região central do Rio Grande do Sul. As alíquotas de leite foram enviadas sem resfriamento, com adição do conservante Bronopol (2-bromo-2nitropropane-1, 3-diol). Para a realização dos testes sorológicos, as amostras de leite foram previamente centrifugadas a $3.000 \mathrm{xg}$ por $15 \mathrm{~min}$ a $4^{\circ} \mathrm{C}$. A fase aquosa situada abaixo da camada de gordura foi coletada e inativada a $56^{\circ} \mathrm{C}$ por $30 \mathrm{~min}$. As amostras de soro foram submetidas ao mesmo tratamento de inativação.

\section{Pesquisa de anticorpos}

Amostras de soro foram testadas para a presença de anticorpos neutralizantes contra o BVDV em paralelo, através das técnicas de soro-neutralização tradicional (SN) e soro-neutralização rápida (SNR). As amostras de leite foram testadas através da SNR.

Soro-neutralização (SN). Os testes foram realizados em placas de poliestireno de 96 cavidades, utilizando uma diluição constante do soro (1:10) frente à $100 \mathrm{DICC}_{50}$ (doses infectantes para $50 \%$ dos cultivos celulares/cavidade) da cepa de BVDV citopática Singer. A quantificação dos anticorpos foi realizada pela incubação de diluições na base 2 crescentes do soro frente a doses constantes do vírus. Após incubação da mistura soro-vírus por $2 \mathrm{~h}$ a $37^{\circ} \mathrm{C}$, uma suspensão de células MDBK foi adicionada, seguida de incubação em estufa de $\mathrm{CO}_{2}$ a $37^{\circ} \mathrm{C}$. A leitura dos testes foi realizada após $96 \mathrm{~h}$ de incubação, através do monitoramento do efeito citopático (ECP). Nos testes qualitativos, a ausência de ECP indicou neutralização viral na diluição utilizada. Nos testes quantitativos, foram considerados títulos de anticorpos neutralizantes as recíprocas das maiores diluições do soro capazes de inibir a replicação viral e a conseqüente produção de ECP.

Soro-neutralização rápida (SNR). Alíquotas de soro ou leite foram diluídas 1:10 em MEM contendo 100 DICC $_{50}$ do vírus por $2 \mathrm{~h}$ a $37^{\circ} \mathrm{C}$. Ao final desse período, uma suspensão de células MDBK foi adicionada e homogeneizada com a mistura soro-vírus ou leite-vírus. Uma alíquota dessa suspensão $(50 \mathrm{~mL})$ foi então depositada sobre uma área circular de $3 \mathrm{~mm}$ de diâmetro delimitada por Teflon em lâminas de microscopia do tipo multispot. As lâminas foram incubadas em câmara úmida em estufa de $\mathrm{CO}_{2}$ a $37^{\circ} \mathrm{C}$ durante $20 \mathrm{~h}$. As lâminas contendo os tapetes celulares foram fixadas em acetona gelada por $5 \mathrm{~min}$, secas ao ar e submetidas à imunofluorescência indireta (IFA) para a detecção de antígenos virais. $O$ teste de IFA foi realizado de acordo com protocolo-padrão (Flores \& Donis 1995), utilizando-se um anticorpo monoclonal anti-BVDV (Kreutz et al. 2000) como anticorpo primário e um conjugado anti-lgG de camundongo/FITC (Sigma). Amostras sabidamente positivas de soro e leite foram utilizadas como controles. A detecção de antígenos virais nas células inoculadas com as respectivas diluições do soro ou leite indicou a ausência de neutralização viral.

Os resultados dos testes de 1.335 amostras de soro obtidos na SNR foram comparados com os resultados obtidos na técnica de SN tradicional. Os parâmetros sensibilidade, especificidade, valores preditivos positivos e negativos da SNR foram calculados de acordo com Coggon et al. (1993) e o índice de concordância (k) foi calculado e interpretado de acordo com Riegelman et al. (1991).

\section{RESULTADOS}

Os resultados dos testes de soro-neutralização tradicional (SN) e do teste rápido (SNR) realizados em paralelo em 1335 amostras de soro bovino estão apresentados no Quadro 1. Os dois testes produziram resultados iguais em 1.216 amostras $(91,1 \%)$, sendo 639 positivas e 577 negativas. 0 teste modificado apresentou sensibilidade de $93,7 \%$; especificidade de $88,4 \%$; valor preditivo positivo $89,4 \%$ e valor preditivo negativo de $93,1 \%$ em relação ao teste tradicional. O índice de concordância $k$ entre os testes foi de 0,81 , o que indica correlação muito boa entre as técnicas (Riegelman et al. 1981). O teste rápido detectou 76 amostras positivas a mais do que o teste tradicional, mas falhou em detectar 43 amostras que foram positivas na SN. Dentre essas últimas, 41 apresentavam títulos de 10 e duas apresentavam títulos de 20 (dados não apresentados). A técnica de SNR foi também utilizada

Quadro 1. Comparação das técnicas de soro-neutralização (SN) e soro-neutralização rápida (SNR) para a detecção de anticorpos contra o vírus da Diarréia Viral Bovina (BVDV) em amostras de soro bovino

\begin{tabular}{lcccc}
\hline \multicolumn{1}{c}{ Técnica } & & \multicolumn{3}{c}{ Soroneutralização rápida (SN) } \\
\cline { 3 - 5 } & & Positivos & Negativos & Total \\
\hline \multirow{2}{*}{ Soro-neutralização } & Positivos & 639 & 76 & 715 \\
rápida (SNR) & Negativos & 43 & 577 & 620 \\
& Total & 682 & 653 & 1335
\end{tabular}

Quadro 2. Comparação entre as técnicas de soro-neutralização (SN) e técnica rápida de soro-neutralização (SNR) para detecção de anticorpos neutralizantes contra o vírus da Diarréia Viral Bovina

(BVDV) em amostras de soro e leite de vacas em lactação

\begin{tabular}{lcccc}
\hline \multicolumn{1}{c}{ Técnica } & & \multicolumn{3}{c}{ Anticorpos no leite (SNR) } \\
\hline Anticorpos & Positiva & Positivas & Negativas & Total \\
no soro (SN) & Negativas & $398(76,3 \%)$ & $63(12,3 \%)$ & 461 \\
\multicolumn{1}{c}{ Total } & & $7(1,3 \%)$ & $52(10 \%)$ & 59
\end{tabular}

Quadro 3. Deteç̧ão de anticorpos neutralizantes contra o vírus da Diarréia Viral Bovina (BVDV), através da técnica rápida de soroneutralização (SNR) em amostras de leite de vacas soropositivas para o BVDV

\begin{tabular}{cccc}
\hline \multirow{2}{*}{$\begin{array}{c}\text { Título } \\
\text { Sérico }\end{array}$} & $\mathrm{n}$ & \multicolumn{2}{c}{ Anticorpos no leite } \\
\cline { 3 - 4 }$\geq 320$ & & $191(97,4)$ & $5(2,6)$ \\
\hline Positivos $^{\mathrm{b}}(\%)$ & Negativos (\%) \\
\hline 80 & 85 & $79(92,9)$ & $6(7,1)$ \\
40 & 67 & $59(88)$ & $8(12,0)$ \\
20 & 52 & $40(76,9)$ & $12(23,1)$ \\
10 & 31 & $19(61,3)$ & $12(38,7)$ \\
Total & 461 & $10(33,3)$ & $20(64,7)$ \\
& & $398(86,3)$ & $63(13,7)$
\end{tabular}

a Título de anticorpos neutralizantes no soro, através da técnica de soroneutralização.

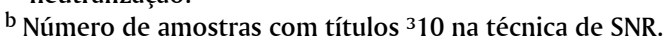


para testar 423 amostras de soro que apresentaram toxicidade para as células na SN tradicional. Das amostras testadas, 316 $(74,7 \%)$ foram positivas no teste de SNR. Amostras de soro e leite de 520 vacas em lactação foram testadas pela técnica de SN (soro) e SNR (leite) para verificar a associação entre soropositividade e presença de anticorpos no leite. De 461 amostras de leite de vacas soropositivas ao BVDV, 397 animais $(86,1 \%)$ possuiam atividade neutralizante anti-BVDV no leite (Quadro 2). Sessenta e quatro amostras de leite $(12,3 \%)$ de animais soropositivos foram negativas na SNR. Dentre as amostras de leite de 59 animais soronegativos examinadas, $52(88,1 \%)$ eram negativas para anticorpos, mas 7 amostras $(11,8 \%)$ foram positivas na SNR. Essas amostras possuiam título de 10 na SNR. Considerando a técnica de SN para a detecção de anticorpos no soro como referência, esses resultados indicam a ocorrência de $7(1,34 \%)$ falsos-positivos e 64 $(12,3 \%)$ falsos-negativos na SNR.

Para investigar uma possível associação entre títulos séricos e positividade na SNR (leite), as amostras de soro de 461 vacas que foram positivas na SN (diluição de 1:10) foram submetidas à quantificação dos anticorpos através de SN quantitativa, utilizando diluições crescentes do soro frente à doses constantes do vírus. Os resultados estão apresentados no Quadro 3. Os testes de amostras de soro e leite de vacas soropositivas demonstraram que a técnica de SNR é capaz de detectar anticorpos no leite de vacas que possuem títulos a partir de 10. No entanto, animais com títulos séricos entre 10 e 40 freqüientemente não apresentam níveis detectáveis de anticorpos no leite, como demonstrado pelo percentual geral de amostras negativas nos animais com esses títulos (Quadro 3). Em animais com títulos séricos a partir de 80, a correlação entre soropositividade e presença de anticorpos no leite aumentou progressivamente. A freqüência de positividade no teste do leite variou com os títulos séricos, entre 33,3\% (10/30) em vacas com títulos de 10 e 97,4\% (191/ 196) em animais com títulos $\geq 320$.

\section{DISCUSSÃO}

A redução do tempo de incubação do teste de $\mathrm{SN}$, viabilizada pela detecção de antígenos virais por imunofluo-rescência, minimizou os efeitos tóxicos para as células de cultivo permitindo a pesquisa de anticorpos contra o BVDV em amostras de leite. A adaptação da técnica também permitiu o teste de amostras tóxicas de soro, além de reduzir significativamente o tempo para obtenção dos resultados. A possibilidade de se identificar rebanhos com atividade viral através do exame de amostras de leite coletadas de recipientes coletivos pode representar um avanço importante para o controle da infecção pelo BVDV em gado leiteiro, principalmente no Brasil, onde o teste de ELISA para a deteç̧ão de anticorpos no leite ainda não é utilizado.

A técnica de SNR foi padronizada em amostras de soro, comparando-se os seus resultados com os resultados da SN tradicional. Durante a padronização, as possíveis conseqüências da redução do tempo de incubação foram investigadas, pois a incubação de $20 \mathrm{~h}$ poderia ser insuficiente para a produção de antígenos virais em quantidades detectáveis pela
IFA. Isso pode explicar parte dos 76 resultados positivos na SNR e negativos na SN (Quadro 1). No entanto, o teste de 228 amostras de soro de rebanhos negativos para o BVDV através da SNR não resultou em nenhum resultado positivo (resultados não mostrados). Da mesma forma, 41 das 43 amostras de soro identificadas como positivas apenas na SN tradicional apresentavam títulos baixos (1:10). Portanto, as discrepâncias nos resultados dos testes ocorreram quase exclusivamente em amostras de soro com níveis baixos de anticorpos e certamente refletem diferenças de sensibilidade entre as técnicas. Como a SNR destina-se a detectar amostras de leite com títulos altos, a falha em detectar amostras com títulos baixos de anticorpos não compromete a sua utilização.

O desenvolvimento de um teste ELISA para a detecção de anticorpos anti-BVDV em amostras coletivas de leite (Niskanen et al. 1991), aliado à correlação existente entre o nível de anticorpos no leite e a proporção de animais soropositivos nos rebanhos (Niskanen 1993, Beaudeau et al. 2001), tem impulsionado programas de vigilância, controle e erradicação da infecção pelo BVDV nos países escandinavos (Paton et al. 1998, Lindberg \& Alenius 1999). Testes sorológicos em amostras coletadas de recipientes coletivos têm sido utilizados para triagem inicial dos rebanhos. De acordo com os níveis de anticorpos no leite (valores de absorbância no teste de ELISA), os rebanhos são classificados em classes (0 a 5 ) (Niskanen 1993). Esses valores refletiriam a proporção de vacas soropositivas e os níveis de anticorpos nesses animais, podendo-se inferir a presença ou não de atividade viral e a provável presença de animais PI (Niskanen et al. 1991, Niskanen 1993, Lindberg \& Alenius 1999). Recentemente, um teste ELISA capaz de detectar mesmo rebanhos com baixa prevalência de vacas em lactação soropositivas ao BVDV foi descrito (Beaudeau et al. 2001).

O objetivo principal da adaptação do teste de SN para a pesquisa de anticorpos anti-BVDV no leite foi viabilizar a sua utilização para triagem de rebanhos leiteiros. O monitoramento sorológico dos rebanhos através de exames do leite deve ser combinado com procedimentos adicionais para a identificação dos animais PI nas propriedades que apresentem níveis sorológicos elevados (Niskanen 1993, Paton et al. 1998, Lindberg \& Alenius 1999). Para isso, as amostras que forem positivas no teste qualitativo (Diluição 1:10 ou maior, de acordo com o nível que se deseje detectar) devem ser posteriormente tituladas (através de um teste quantitativo de neutralização viral). Os rebanhos com níveis altos de anticorpos serão o alvo de procedimentos subseqüientes, pois possuem atividade viral recente e potencialmente possuem animais PI (Niskanen 1993, Houe 1995). A presença de animais PI pode ser confirmada através de isolamento do vírus de animais com idade entre 8 e 24 meses (Lindberg \& Alenius 1999).

Os países europeus que utilizam a detecção de anticorpos no leite para triagem de rebanhos não utilizam vacinação contra o BVDV. Nesses casos, resultados positivos no teste indicam necessariamente resposta à infecção natural (Niskanen 1993, Lindberg \& Alenius 1999). No Brasil, embora a vacinação contra o BVDV seja praticada em uma parcela 
relativamente pequena dos rebanhos, anticorpos vacinais podem potencialmente ser detectados pelo teste. Nesses casos, a identificação de rebanhos positivos pela triagem deve ser seguida de investigação do status vacinal de cada rebanho para determinar-se a origem da sorologia positiva.

A frequiência de animais soropositivos que apresentou anticorpos detectáveis no leite $(329 / 397$ ou $86,1 \%)$ deve ser interpretada com cautela, pois a proporção de animais com títulos altos $(160,3320)$ examinada $(281 / 420)$ foi muito alta. Como pode ser observado no Quadro 3, a frequiência de positividade no leite aumenta com os títulos séricos. Animais com títulos séricos altos são freqüentemente positivos no teste do leite, ao contrário de animais com títulos progressivamente inferiores, que são detectados com menor freqüiência na SNR. Inclusive, vários animais soropositivos $(n=63)$ foram negativos no teste do leite, provavelmente portadores de baixos títulos séricos. Além desses falsos-negativos na SNR, amostras de leite de alguns animais soronegativos na $\mathrm{SN}$ (Diluição de 1:10) foram positivas na SNR. A titulação dos anticorpos no leite desses animais revelou títulos de 10 . A ocorrência de falsos-positivos na SNR pode ser devida a diferenças de sensibilidade entre as técnicas ou à presença de fatores neutralizantes virais não-específicos no leite, ou ambos. De qualquer forma, esses falsos-positivos na SNR representaram uma pequena parcela das amostras, além de apresentarem títulos neutralizantes baixos no leite. Considerando-se a detecção paralela de anticorpos no leite (SNR) e soro (SN), a sensibilidade da SNR $(98,3 \%)$ foi superior ao índice de 95\% relatado para um ELISA desenvolvido para detectar anticorpos em amostras coletivas de leite (Beaudeau et al. 2001). O grande número de falsos-negativos na SNR, no entanto, contribuiu para a baixa especificidade $(45,2 \%$ do teste). Com base nos resultados obtidos pelo teste paralelo de soro-leite (Quadro 3), é provável que a maioria desses falsosnegativos na SNR sejam animais soropositivos com títulos séricos baixos.

Além de diferenças de sensibilidade entre as técnicas de SN e SNR, outros fatores podem ter contribuido para as discrepâncias nos resultados dos testes paralelos soro/leite. A presença, e os níveis de imunoglobulinas no leite podem ser influenciados pelos níveis séricos de anticorpos, estágio de lactação, produção leiteira e presença de reações inflamatórias na glândula mamária, entre outros (McGuire et al. 1975, Perino et al. 1995). Portanto, embora exista uma certa correlação entre níveis séricos e lácteos de anticorpos específicos para o BVDV, o grau dessa correlação parece ser influenciado por outros fatores que devem ser melhor investigados.

Embora a SNR falhe em detectar anticorpos no leite de uma parcela considerável de vacas que são soropositivas ao BVDV (sobretudo de animais com títulos séricos baixos e moderados), o seu objetivo maior justifica a sua utilização. $O$ teste de amostras coletivas de leite através da SNR visa detectar rebanhos com atividade viral atual ou recente. Esses rebanhos geralmente possuem vários animais soropositivos em lactação, ou alguns animais com títulos altos. Rebanhos com poucos animais soropositivos, e com títulos baixos ou moderados de anticorpos, geralmente não possuem animais
PI e portanto não constituem-se em alvo de estratégias de controle/erradicação da infeç̧ão (Niskanen 1993).

A redução do tempo de incubação também viabilizou o teste de amostras de soro que apresentaram toxicidade para as células na SN tradicional. Dentre 11.210 amostras de soro enviadas ao Laboratório de Virologia da UFSM para sorologia do BVDV entre 1998 e 2000, 1.077 (9,6\%) foram tóxicas para o cultivo e não puderam ser testadas na ocasião (Dados não publicados). Portanto, a toxicidade é um achado freqüiente em amostras de soro enviadas para diagnóstico, o que muitas vezes impossibilita o seu exame. A partir da modificação da técnica, amostras de soro que apresentarem toxicicidade no teste de SN poderão ser retestadas pela SNR. A redução do tempo para obtenção dos resultados constitui-se em outro aspecto positivo da técnica modificada. $O$ teste pode ser completado em $24 \mathrm{~h}$, enquanto a $\mathrm{SN}$ tradicional requer entre 72 e 96 h para leitura dos resultados.

Em resumo, a técnica de SNR para a deteç̧ão de anticorpos no leite pode constituir-se em uma importante ferramenta para o monitoramento de rebanhos e o combate à infeç̧ão pelo BVDV em gado leiteiro. Quando aplicado a amostras coletivas de leite, o teste permitirá a identificação de rebanhos com atividade viral e potencialmente portadores de animais PI. A técnica pode ser aplicada também em estudos epidemiológicos, podendo fornecer informações sobre a prevalência e distribuição dos rebanhos positivos para o BVDV.

Agradecimentos.- Aos técnicos da Usina-Escola de Laticínios da UFSM (Convênio COPROL-UFSM) pela disponibilização das amostras de leite. Aos estudantes Mário Celso S. Brum e Evandro R. Winkelmann pelo auxílio na coleta e processamento das amostras.

\section{REFERÊNCIAS}

Alenius S., Lindberg A. \& Larsson B. 1996. A national approach to the control of bovine viral diarrhoea virus. In: Edwards S., Paton D.J. \& Wensvoort G. (Ed.) Proc. $3^{\text {rd }}$ European Society for Veterinary Virology Symposium: Pestivirus Infections, 19-20 Sept., Lelystad, Netherlands, p. 162-169.

Baker J.C. 1995. The clinical manifestations of bovine viral diarrhea virus infection. Vet. Clin. North America 11:425-446.

Beaudeau F., Belloc C., Seegers H., Assie S., Pourquier P. \& Joly A. 2001. Informative value of an indirect enzyme-linked immunosorbent assay (ELISA) for the detection of bovine viral diarrhoea virus (BVDV) antibodies in milk. J. Vet. Med. B 48(9):705-712.

Botton S.A., Silva A.M., Brum M.C.S., Weiblen R. \& Flores E.F. 1998. Antigenic characterization of Brazilian isolates of bovine viral diarrhea virus (BVDV) with monoclonal antibodies and by cross-neutralization. Braz.J. Med. Biol. Res. 31:1429-1438.

Brock K.V. 1995. Diagnosis of bovine viral diarrhea virus infections. Vet. Clin. North America 11:549-562.

Brownlie J. 1990. The pathogenesis of bovine viral diarrhea virus infections. Vet. Sci. Tech. 9:43-59.

Coggon T., Rose G. \& Barker D.J. 1993. Measurement error and bias, p. 20-25. In: Epidemiology for the Unitiated. $3^{\text {rd }}$ ed. British Medical Journal.

Corapi W.V., Moennig V. \& Horzinek M. 1989. Recent advances in pestivirus research. J. Gen. Virol. 70:253-266.

Dubovi E.J. 1992. Genetic diversity and BVD virus. Comp. Immun. Microbiol. Dis. 15:155-162.

Flores E.F. \& Donis R. 1995. Isolation of a mutant MDBK cell line resistant to bovine viral diarrhea virus infection due to a block in viral entry. Virology 208:565-575. 
Francki R.I.B., Fauquet C.M., Knudson D.L. \& Brown F. 1991. Classification and nomenclature of viruses. Fifth Report of the International Committee on the Taxonomy of Viruses. Arch. Virol.(Suppl. 2):223-233.

Houe H. 1995. Epidemiology of bovine viral diarrhea virus. Vet. Clin. North America 11:521-548.

Kreutz L.C., Donis R., Gil L.H.V., Lima M., Hoffman A.N., Garcez D.C., Flores E.F. \& Weiblen R. 2000. Production and characterization of monoclonal antibodies to Brazilian isolates of bovine viral diarrhea virus. Braz. J. Med. Biol. Res. 33:1459-1466.

Lindberg A. \&, Alenius S. 1999. Principles for eradication of bovine viral diarrhoea virus (BVDV) infections in cattle populations. Vet. Microbiol. 64:197-222.

McGuire T.C., Crawford T.B. \& Hallowell A.L. 1975. Hypogammaglobulinemia predisposing to infection in foals. J. Am. Vet. Med. Assoc. 166:71-75.

Niskanen R. 1993. Relationship between the levels of antibodies to bovine viral diarrhoea virus in bulk tank milk and the prevalence of cows exposed to the virus. Vet. Rec. 133:341-344.

Niskanen R., Alenius S., Larsson B. \& Jacobsson S.O. 1991. Determination of level of antibodies to bovine virus diarrhoea virus (BVDV) in bulk tank milk as a tool in the diagnosis and prophylaxis of BVDV infections in dairy herds. Arch. Virol. (Suppl. 3):245-51.
Paton D.J., Christiansen K.H., Alenius S., Cranwell M.P., Pritchard G.C. \& Drew T.W. 1998. Prevalence of antibodies to bovine virus diarrhoea virus and other viruses in bulk tank milk in England and Wales. Vet. Rec. 4:385391.

Perino L.J., Wittum T.E. \& Ross G.S. 1995. Effects of various risk factors on plasma protein and serum immunoglobulin concentrations of calves at post partum hours 10 and 24. Am. J. Vet. Res. 56:1144-1148.

Pituco E.M. \& Del Fava C. 1998. Situação do BVDV na América do Sul. Proc. Simpósio Internacional sobre Herpesvírus Bovino (tipo 1 e 5) e vírus da Diarréia Viral Bovina (BVDV), Santa Maria, RS, p. 49-57.

Riegelman A .K. \& Hirch A . P. 1991. Como estudiar un estudio y probar una proba: lectura crítica de la literatura médica. Boln Of. San. Panam. 11: 534555.

Roehe P.M., Oliveira E.A.S., Oliveira L.G. \& Munoz J.C.P. 1998. A situação do vírus da Diarréia Viral Bovina no país. Proc. Simpósio Internacional sobre Herpesvírus Bovino (tipo 1 e 5) e vírus da Diarréia Viral Bovina (BVDV), Santa Maria, RS, p. 39-48.

Vogel F.S.F., Flores E.F., Weiblen R., Mayer S.V. \& Quadros V.L. 2002. Magnitude, duração e especificidade da resposta sorológica induzida em bovinos vacinados contra o vírus da Diarréia Viral Bovina (BVDV). Ciêncial Rural, Santa Maria, 32(1):83-89. 